\title{
Re-intervention for stent-stone complex using intraductal cholangioscopy with electrohydraulic lithotripsy after multiple biliary metal stenting
}

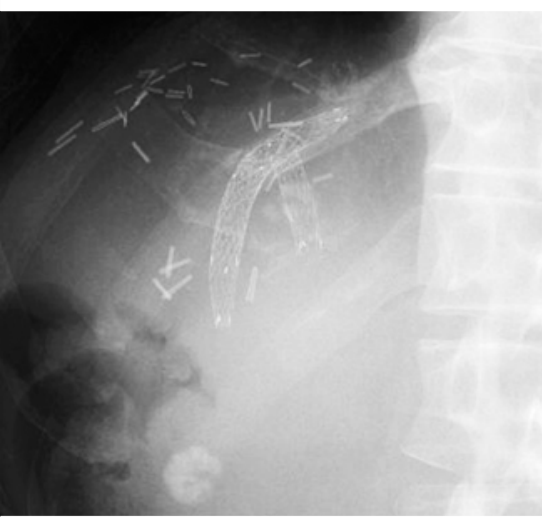

- Fig. 1 The distal end of the previously placed metal stent was tapering, and therefore, it was not possible to insert the guidewire into the stent lumen.

A man in his 40s who had undergone right lobectomy for hepatocellular carcinoma, developed jaundice due to hilar biliary obstruction associated with recurrence of the cancer. Multiple metal stents were placed for the ventrolateral and dorsolateral segmental ducts, using a partial stent-in-stent method.

At 5 months after the procedure, jaundice recurred with intrahepatic bile duct dilation, and the patient underwent endoscopic re-intervention. However, the guidewire could not be inserted into the lumen of the previously placed metal stent. The distal stent end was found to be tapering ( $\mathbf{F i g . 1}$ ), and ingrowth with/without overgrowth was suspected, based on X-ray fluoroscopic findings.

Following insertion of a digital intraductal cholangioscope (SpyGlass DS; Boston Scientific Corp., Marlborough, Massachusetts, USA) into the bile duct, it was found that a stent-stone complex had formed at the distal stent end, and the lumen of the stent was completely obstructed (\$ Fig.2). Therefore, electrohydraulic lithotripsy was performed for the stent-stone complex. Thereafter, the lumen was visualized, and the guide-
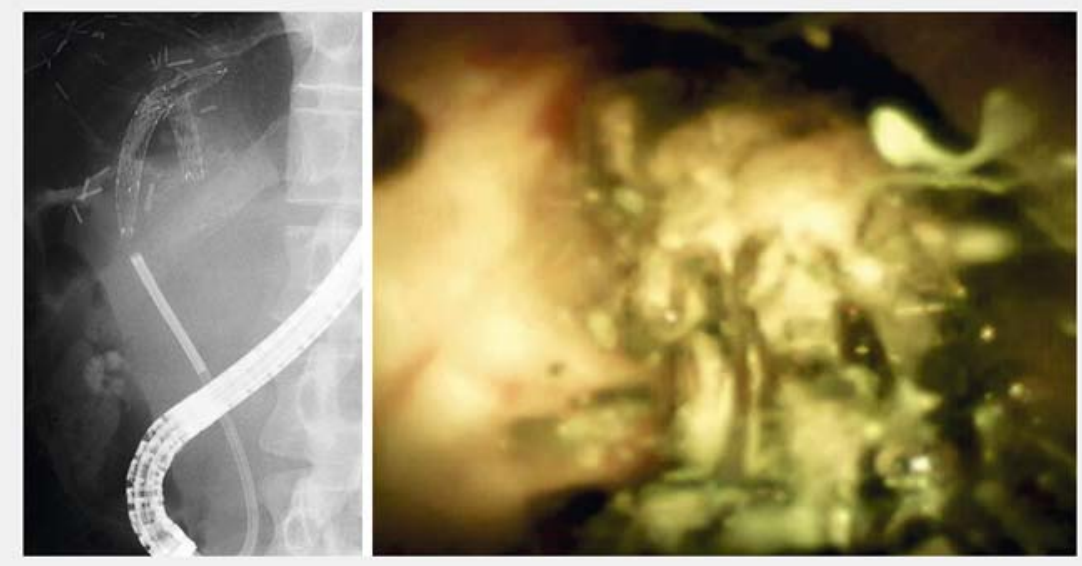

Fig. 2 Cholangioscopy showed formation of a stent-stone complex at the distal stent end, with complete obstruction of the stent lumen.

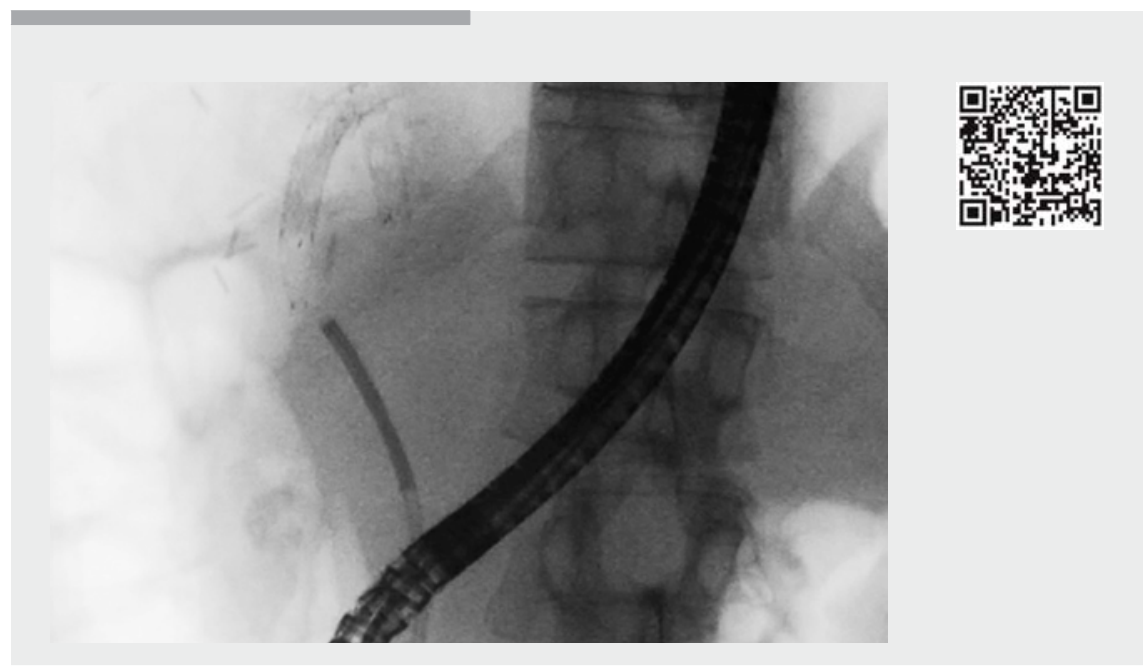

Video 1 Stent-stone complex seen at the distal stent end on insertion of the digital intraductal cholangioscope into the bile duct. Electrohydraulic lithotripsy was performed, with subsequent visualization of the stent lumen. The guidewire was then inserted under cholangioscopic guidance.

wire was inserted under cholangioscopic guidance ( $\triangleright$ Video 1$)$.

Subsequently, stone fragments were removed using a balloon and basket catheter, and a stent was placed into the ventrolateral segmental duct. The patient's symptoms and laboratory values showed improvement postoperatively, with no adverse events.

Recurrent biliary obstruction mainly occurs due to ingrowth/overgrowth after placement of uncovered metal stents for malignant hilar biliary obstruction [13]. Stent-stone complex is rare, but this 
might be related to difficulty in the diagnosis of radiolucent stones [4]. In the present case, cholangioscopy was useful for the diagnosis, and appropriate re-intervention could be performed using electrohydraulic lithotripsy and guidewire placement under cholangioscopic guidance.

In summary, when the guidewire cannot be inserted into the stent lumen after placement of a metal stent, cholangioscopy should be considered, as stentstone complex is one of the differential diagnoses.

Endoscopy_UCTN_Code_CPL_1AK_2AC

Competing interests

None

The authors

Tadahisa Inoue, Yukiomi Nakade, Rena Kitano, Yuji Kobayashi, Norimitsu Ishii, Kiyoaki Ito, Masashi Yoneda

Department of Gastroenterology, Aichi Medical University, Aichi, Japan
Corresponding author

\section{Tadahisa Inoue, MD}

Department of Gastroenterology, Aichi Medical University, 1-1 Yazakokarimata, Nagakute, Aichi 480-1195, Japan

Fax: +81-561-633208

tinoue-tag@umin.ac.jp

\section{References}

[1] Mukai T, Yasuda I, Nakashima M et al. Metallic stents are more efficacious than plastic stents in unresectable malignant hilar biliary strictures: a randomized controlled trial. J Hepatobiliary Pancreat Sci 2013; 20: 214 222

[2] Inoue T, Naitoh I, Okumura F et al. Reintervention for stent occlusion after bilateral self-expandable metallic stent placement for malignant hilar biliary obstruction. Dig Endosc 2016; 28: 731 - 737

[3] Tomoda T, Kato H, Kawamoto H et al. Usefulness of a newly designed plastic stent for endoscopic re-intervention in patients with malignant hilar biliary obstruction. Endoscopy 2017; 49: $1087-1091$

[4] Tang S], Amstrong L, Lara LF et al. De novo stent-stone complex after long-term biliary stent placement: pathogenesis, diagnosis, and endotherapy. Gastrointest Endosc 2007; 66: $193-200$

\section{Bibliography}

DOI https://doi.org/10.1055/a-0584-6171

Published online: 22.3.2018

Endoscopy 2018; 50: E138-E139

(c) Georg Thieme Verlag KG

Stuttgart · New York

ISSN 0013-726X

\section{ENDOSCOPY E-VIDEOS}

https://eref.thieme.de/e-videos

Endoscopy E-Videos is a free access online section, reporting 靣触: on interesting cases and new

techniques in gastroenterological endoscopy. All papers include a high quality video and all contributions are freely accessible online.

This section has its own submission website at https://mc.manuscriptcentral.com/e-videos 